\title{
Rare earths: jewels for functional materials of the future $\dagger$
}

\author{
Svetlana V. Eliseeva ${ }^{a b}$ and Jean-Claude G. Bünzli ${ }^{a c}$ \\ Received (in Montpellier, France) 7th December 2010, Accepted 6th January 2011 \\ DOI: $10.1039 / \mathrm{conj00969e}$
}

In recent decades, rare earths have become vital to a wealth of advanced materials and technologies including catalysts, alloys, magnets, optics and lasers, rechargeable hydride batteries, electronics, economical lighting, wind- and solar-energy conversion, bio-analyses and imaging. In this perspective article we give a broad overview of rare earth resources and uses first and then of selected applications in dedicated fields such as telecommunications, lasers, photovoltaics (solar-energy conversion), lighting (fluorescent lamps and OLEDs), luminescent probes for bio-analyses and bio-imaging, as well as magnetism and magnetic refrigeration.

\section{Rare-earths and technology}

The stunning story of rare earths (Sc, Y, La-Lu, Fig. 1) starts in 1787 when lieutenant Carl Axel Arrhenius from the Royal Swedish Army, who was an amateur geologist, discovered a curious black stone in a quarry located in the vicinity of Ytterby, near Waxholm's fortress on Resarö island, about $22 \mathrm{~km}$ from Stockholm. Analysis of this heavy stone ("tung sten" in Swedish) by mineralogist B. R. Geijer confirmed that it was a new mineral which was named "ytterbite". In 1894, Johan Gadolin, professor at the University of Abø, then in

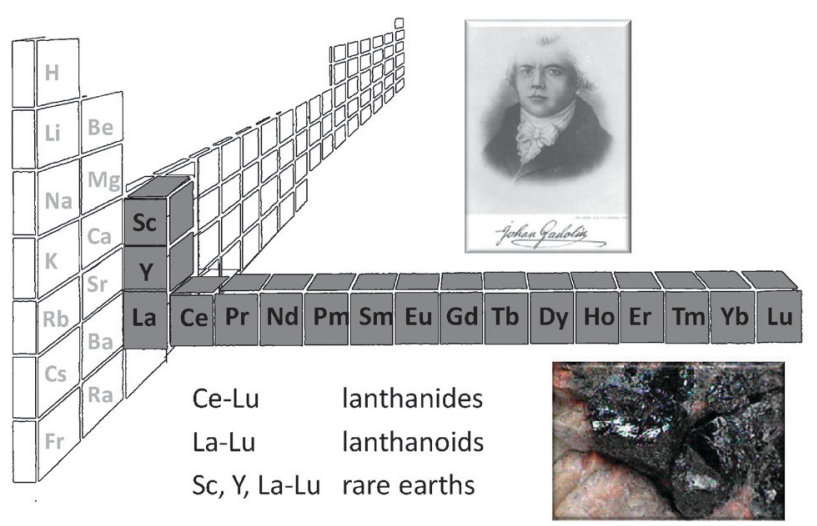

Fig. 1 Position of the rare-earth elements in the periodic table and their official IUPAC nomenclature, a portrait of Johan Gadolin, and a picture of the black stone of Ytterby.

\footnotetext{
${ }^{a}$ École Polytechnique Fédérale de Lausanne, Institute of Chemical Sciences and Engineering, BCH 1402, CH-1015 Lausanne,

Switzerland. E-mail: jean-claude.bunzli@epfl.ch

${ }^{b}$ Katholieke Universiteit Leuven, Department of Chemistry, Laboratory of Coordination Chemistry, Celestijnenlaan 200F, BUS 2404, B-3001 Leuven, Belgium

${ }^{c}$ Korea University, Center for Next Generation Photovoltaic Systems, Jochiwon-eup, Yeongi-gun, Chungnam-do 339-700, South Korea

$\dagger$ This article is part of a themed issue on Molecular Materials: from Molecules to Materials, commissioned from the MolMat2010 conference.
}

Sweden but today belonging to Finland and known as Turku, discovered a new element in it, yttrium (Fig. 1). These facts initiated a series of investigations by the most brilliant European scientists which eventually led to the identification of 15 other rare-earth elements between 1803 (cerium) and 1907 (lutetium), the last, radioactive one being synthesized in 1947 at the Oak Ridge National Laboratory.

During more than a century, rare earths did not find practical applications, aside from the tremendous stimulation they brought to science and technology in general and to spectroscopy in particular. This dramatically changed when Austrian entrepreneur Carl Auer von Welsbach, the discoverer of praseodymium and neodymium, filed two patents. The first one (1901) described an incandescent gas mantle made up of thorium oxide doped with $1 \%$ of tetravalent cerium oxide. The second one (1903) dealt with the production of flint stones from "Mischmetall", an alloy of 30\% iron and 70\% La, Ce, $\mathrm{Nd}$, and $\mathrm{Sm}$. The long love story between rare earths and lighting applications was born! In recent decades, rare earths have become vital to a wealth of advanced materials and technologies including catalysts, alloys, magnets, optics and lasers, rechargeable hydride batteries, electronics, economical lighting, wind- and solar-energy conversion, bio-analyses and imaging. Many objects around us contain rare earths: cars, cell phones, electronic displays, fluorescent lamps, light emitting diodes (LEDs), optical fibres, micro-motors, medical scanners, among others and not to mention military applications such as guidance systems and night-vision binoculars.

A peculiar aspect of rare-earth applications is that they sometimes do not involve large quantities, several materials owing their special properties to simple doping of rare earths at low concentration, e.g. $35 \mathrm{ppm}$ of $\mathrm{Er}_{2} \mathrm{O}_{3}$ doped in silica optical fibres. The annual consumption in 2009 is estimated to 124000 metric tons of equivalent rare-earth oxides for a total worth of 1.2 billion US dollars. Three major applications, catalysts (mainly cracking catalysts), alloys (such as Mischmetall), and magnets $\left(\mathrm{SmCo}_{5}\right.$ and $\mathrm{Fe}_{14} \mathrm{Nd}_{2} \mathrm{~B}$ ), 


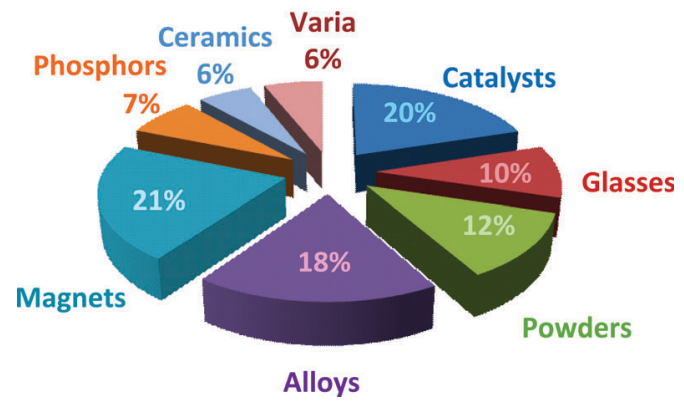

Fig. 2 Weight percentages of rare earths used in their principal industrial applications in 2009 (data are from the US Geological Survey).

account for about $60 \%$ of this tonnage (Fig. 2). Three others, polishing powders for screens, lenses and windows, optical glasses for lenses and lasers, as well as light-converting phosphors for fluorescent lamps, LEDs, displays, and biomedical analyses, account for about $30 \%$. While scientists are proposing more applications there is some concern about a shortage of rare earths worldwide. Indeed, if the abundance of rare earths in the Earth crust is not the lowest of all elements, ranging between $0.5(\mathrm{Tm}, \mathrm{Lu})$ and $60 \mathrm{ppm}(\mathrm{Y})$, their concentration in minerals seldom exceed $8-10 \%$, reaching in rare cases $14-15 \%$. Moreover, these minerals contain a range of rare earths (typically $\mathrm{La}-\mathrm{Eu}, \mathrm{Gd}-\mathrm{Lu}$ ) and given their similar chemical properties, separation of the elements is difficult. All these operations are lengthy, costly and polluting. It is estimated that the world resources are located essentially in China (25-30\%), Russia (about 20-25\%), USA, Canada and Australia (about 20-25\%), while the remaining are scattered in various countries such as India, Vietnam, Malaysia, Sri Lanka, Thailand, Brazil, or Poland. However, during the past 15 years, the production of rare earths has gradually shifted to China which churns out about $96 \%$ of the overall production and therefore completely controls the market, setting up quotas for its customers. Rare-earth substitutes are available for several applications, but they are generally less performing. This risky geopolitical situation is now evolving in that several countries are resuming or starting mining operations and rare-earth production.

All this points to the real challenge faced by developers of new rare-earth-containing materials: generating highly performing functionalities while using a minimum amount of the precious elements. Henceforth the efforts put into elaborating thin films, doped polymers, and nanomaterials.

In this article, we provide a broad overview of the recent scientific developments linked to a few aspects of applications involving rare earths, namely optical materials and probes, as well as magnetic materials. No attempt is made to be comprehensive in view of the overwhelming literature related to these fields, so that we focus on the latest developments only, while mainly citing the numerous review articles which appeared during the past two years, e.g. ref. 1-8.

\section{Telecommunications and lasers}

\subsection{Optical fibres and planar waveguide amplifiers}

In modern telecommunication systems, information is carried by light guided in silica optical fibres. This light is attenuated



Fig. 3 (top) Principle of an EDFA. (bottom) An EDFA unit with $24 \mathrm{~dB} \mathrm{~m}^{-1}$ amplification (reproduced with permission from Aurora Networks, California, USA).

over distance and needs amplification which is mostly achieved by erbium-doped fibre amplifiers (EDFAs, Fig. 3). These devices were invented 30 years ago and operate in the so-called third (or C) communication window (1525-1565 nm). The $\mathrm{Er}^{\mathrm{III}}$ ion has rich spectroscopic properties which are partly described in Fig. 4. In EDFAs, the lanthanide ion is excited either at $980 \mathrm{~nm}$, on the ${ }^{4} \mathrm{I}_{11 / 2}$ level, or at $1480 \mathrm{~nm}$, that is on a metastable crystal-field sub-level of the ${ }^{4} \mathrm{I}_{13 / 2}$ spectroscopic level. This results in a two-level laser emitting in the range $1530-1550 \mathrm{~nm}$ depending on the fine-tuning of the materials. The $980 \mathrm{~nm}$ band has higher absorption cross-section, so it is generally used where low-noise performance is required; the transition is narrow and therefore wavelength-stabilised laser sources are needed. The $1480 \mathrm{~nm}$ band has lower, but broader, absorption cross-section and is typically used for high-power

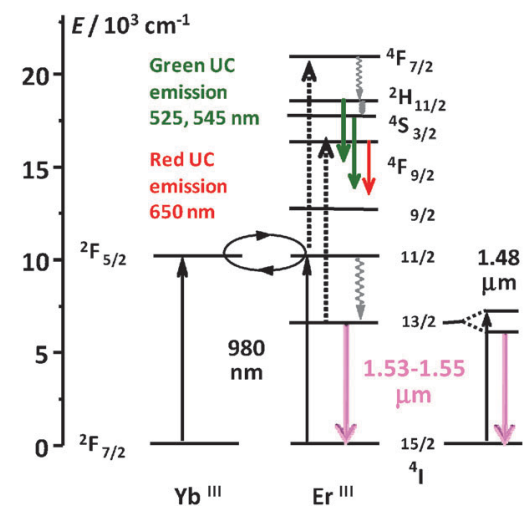

Fig. 4 Excitation and emission paths for the $\mathrm{Er}^{\mathrm{III}}$ ion. 
amplifiers. Most EDFAs, however, use a combination of both pump wavelengths.

In conventional networks, the signal is conveyed by coaxial cables in the end part of the system, as well as inside homes and offices. In 2006, an architecture known as RFoG (radio frequency over glass) has been proposed, in which the $\mathrm{Er}^{\mathrm{III}}$ signal is cost-effectively distributed entirely by glass fibres to the end users, either in low-density population (rural) areas or in single family or multiple dwelling units of new housing developments (Fig. 5). The downstream signals from the broadcast unit are amplified by an EDFA, fed to a wave division multiplexer (WDM) and distributed to the end users up to a distance of $20 \mathrm{~km}$. The return (upstream) signals are carried by 1310 or $1610 \mathrm{~nm}$ light generated by InGaAsP multiple-quantum well structured Fabry-Perot diode lasers, are separated from the downstream signals in the WDM, and converted into radio-frequency packages in a resilient packet ring (RPR) device. In this system, each fibre can support 32 end users; in improved versions, up to 256 subscribers distant up to $60 \mathrm{~km}$ from the broadcast unit can be served by a single fibre (radio-frequency passive optical network, RFPON). The $1310 \mathrm{~nm}$ return signal is a lower cost solution, while the $1610 \mathrm{~nm}$ one is best compatible with the RFPON technology.

One of the limitations of EDFAs is the low absorption cross-section of $\mathrm{Er}^{\mathrm{III}} \mathrm{f}-\mathrm{f}$ transitions on one hand and concentration quenching on the other hand. When the concentration of $\mathrm{Er}^{\mathrm{III}}$ ions is larger than $10^{20} \mathrm{~cm}^{-3}$, both excited state absorption and up-conversion (see Fig. 4, and discussions below) considerably reduce the efficiency of the fibres. There are two ways out to this problem. The first one is to improve the performances of the silica-based fibres by using various hosts, such as alumina instead of silica, as well as by co-doping compounds such as telluride, phosphate or bismuthate. In this way, the emission bandwidth can be broadened, which allows the amplification of more channels in WDM systems, or erbium concentration can be increased without detrimental effects, translating into more compact devices for the same gain, or fibre losses can be reduced. Bismuth-based EDFAs have been tested for high gain compact amplifiers; however, their splicing is difficult, so that zirconium-based EDFAs with comparable performance have been proposed, which eliminate this drawback. ${ }^{9}$

A second solution is to resort to polymer fibres, for instance polymethylmethacrylate (PMMA) fibres in which erbium complexes with organic ligands are doped. The resulting erbium-doped waveguide amplifiers (EDWAs) have definite technical advantages over silica EDFAs: better flexibility and larger diameter, allowing better coupling to local-scale splitters, couplers, and multiplexers, as well as much lower pump threshold. For instance, it has been calculated, using standard parameters for a two-level system, that the threshold power of a PMMA-based fibre is $930 \mathrm{~mW}$ upon direct $\mathrm{Er}^{\mathrm{III}}$ excitation, while pumping through an aromatic cyclic ligand providing a protective cage around the metal ion has a threshold power 660-fold smaller, $1.4 \mathrm{~mW}$ (see section 4.2 in ref. 10). As a result, numerous efforts have been put forward during the past decade to develop such systems. ${ }^{2,10}$

Two main challenges are faced by the designers of EDWAs: adequate dispersion of the $\mathrm{Er}^{\mathrm{III}}$ ions into the polymeric material to avoid concentration quenching and efficient sensitization ${ }^{1}$ of $\mathrm{Er}^{\mathrm{III}}$ luminescence. The first aspect could be dealt with in several ways, including anchoring organic complexes on derivatised polymers or tailoring large dendrimeric complexes ${ }^{11}$ with high absorption coefficients since the overall efficiency of a luminescent compound is the product of its quantum yield and its molar absorption coefficient. The second aspect is much more compelling and, in fact, really governs the overall design of these devices. The observed quantum yield (upon ligand excitation, $Q_{\mathrm{Ln}}^{\mathrm{L}}$ ) is the product between the sensitisation efficiency $\eta_{\text {sens }}$ of the lanthanide luminescence and the intrinsic quantum yield (upon direct f-f excitation, $Q_{\mathrm{Ln}}^{\mathrm{Ln}}$ ) and can be therefore maximized by optimizing the yield of the energy transfer from the ligand to the metal ion while minimizing non-radiative de-activation of the lanthanide ion: ${ }^{2}$

$$
Q_{\mathrm{Ln}}^{\mathrm{L}}=\eta_{\mathrm{sens}} \times Q_{\mathrm{Ln}}^{\mathrm{Ln}}=\eta_{\mathrm{sens}} \times \frac{\tau_{\mathrm{obs}}}{\tau_{\mathrm{rad}}}
$$

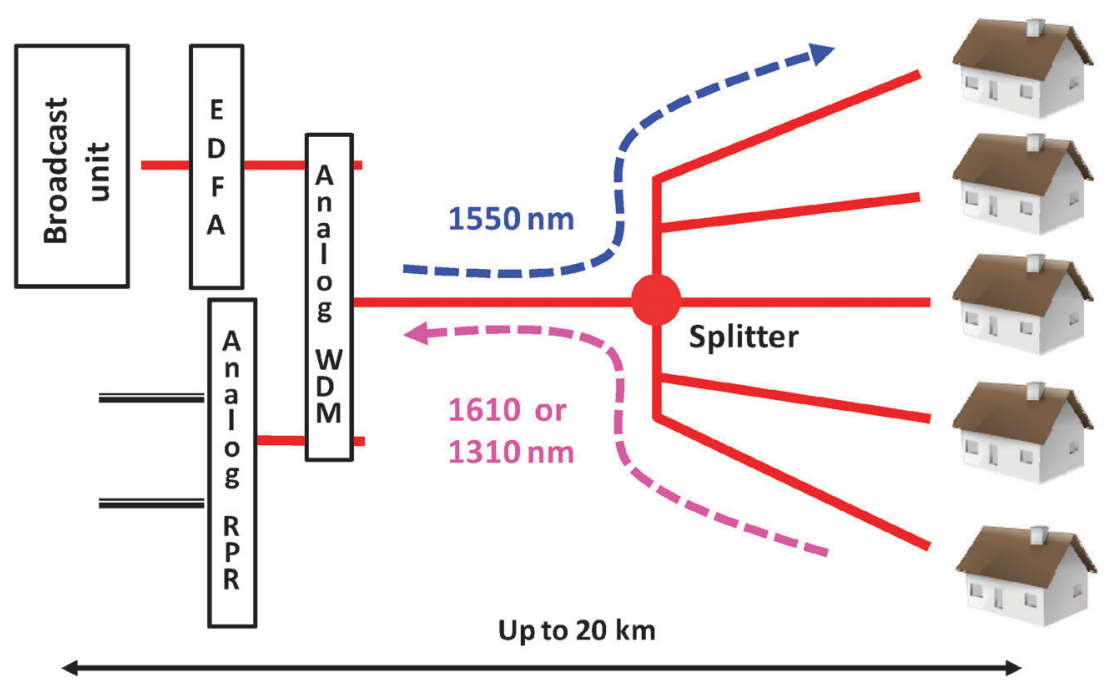

Fig. 5 Sketch of a RFoG network; EDFA $=$ erbium-doped fibre amplifier, WDM $=$ wave-division multiplexer, RPR $=$ resilient packet ring. 
in which $\tau_{\text {rad }}$ and $\tau_{\text {obs }}$ are the radiative and observed lifetimes, respectively. If maximizing $\eta_{\text {sens }}$ can be achieved relatively easily, ${ }^{1}$ minimizing non-radiative de-activations (i.e. maximizing $\tau_{\mathrm{obs}}$ ) is a real conundrum in the case of $\mathrm{Er}^{\mathrm{III}}$. Indeed the ${ }^{4} \mathrm{I}_{13 / 2}{ }^{4} \mathrm{I}_{15 / 2}$ energy gap $\left(\sim 6500 \mathrm{~cm}^{-1}\right)$ can be easily bridged by low overtones of several vibrations, including $\mathrm{C}-\mathrm{H}$ vibrations, even if these groups are not in close proximity to the excited ion. The subject is now well documented both experimentally and theoretically (see section 2.3.3 in ref. 2). Deuteration or fluorination of the ligands improves the situation, but the residual quenching remains large and the longest lifetimes observed are in the range $0.4-0.7 \mathrm{~ms}$, as compared to $12 \mathrm{~ms}$ in silica. There is therefore little hope that all-organic Er ${ }^{\text {III }}$ complexes will be able to overrun the photophysical properties of inorganic systems, although some interesting results have been obtained recently with doped PMMA or SU-8 polymers. ${ }^{2}$ Conversely, in view of the facility of use of EDWAs, there might be several ways out of this dilemma, but most go through the engineering of inorganic-organic hybrid materials. One is to use inorganic clusters with fluorinated thiolates and having reasonably long $\mathrm{Er}-\mathrm{Er}$ distances $(>1.5 \mathrm{~nm})$ or fluorinated iminodiphosphinate complexes. Another solution involves dispersing $\mathrm{Yb}^{\mathrm{III}}-\mathrm{Er}^{\mathrm{III}}$ codoped sodium yttrium tetrafluoride nanoparticles in organic polymers. In this approach, the antenna effect from an organic ligand is replaced by excitation of the $\mathrm{Er}^{\mathrm{III}}$ ion through energy transfer from $\mathrm{Yb}^{\mathrm{III}}$ since $\operatorname{Er}\left({ }^{4} \mathrm{I}_{11 / 2}\right)$ and $\mathrm{Yb}\left({ }^{2} \mathrm{~F}_{5 / 2}\right)$ levels are in resonance (Fig. 4) and since the ${ }^{2} \mathrm{~F}_{5 / 2} \leftarrow{ }^{2} \mathrm{~F}_{7 / 2}$ transition has reasonable intensity. ${ }^{12}$ The advantage of sensitization through $\mathrm{Yb}^{\mathrm{III}}$ is, however, linked to some drawbacks, particularly with respect to increased thermal bleaching ${ }^{13}$ and mechanical stress within the fibre. ${ }^{14}$ Finally, Er ${ }^{\mathrm{III}}$ ions can also be embedded into polyoxometallate or zeolite frameworks which are decorated with or contain organic chromophores. There is no doubt that such avenues will be thoroughly investigated in the near future. ${ }^{15}$

\subsection{Laser materials}

These materials have been among the first applications of lanthanides of high purity and the most widespread rare-earth laser is without any doubt the neodymium YAG (yttrium aluminate garnet containing 1 atom $\%$ of $\mathrm{Nd}^{\mathrm{III}}$ ) device, the $1.06 \mu \mathrm{m}$ emission of which can be easily doubled, tripled, and quadrupled. This laser is ubiquitous in the day-to-day life, from green laser pointers for slide presentations, to medical surgery, manufacturing, engraving, etching, military rangefinders, or nuclear fusion. The vanadate host $\mathrm{YVO}_{4}$ usually provides higher power output, as well as the replacement of $\mathrm{Nd}^{\mathrm{III}}$ with $\mathrm{Yb}^{\mathrm{III}}$. We note that a combination of $\mathrm{Yb}^{\mathrm{III}}$ optical fibre lasers and $\mathrm{Nd}^{\mathrm{III}}$ optical fibre amplifiers is used in the newly open National Ignition Facility at the Lawrence Livermore National Laboratory (USA), generating 500 TW laser pulses for testing deuterium-tritium fusion. All lanthanide-based lasers are solid-state lasers and have trivalent lanthanide ions as lasing medium, although some earlier devices proposed in the 1960 s were made up of divalent samarium. These solid-state lasers are usually pumped by semiconductor diode lasers and offer the advantage, over the latter devices, that scale-up to high power is easy to achieve, as well as wavelength tunability. There are several applications which drive the present research in lanthanide-based lasers, among which are applications in telecommunications, optoelectronic devices, and medical surgery. The field is vast and technical so that we shall not review it in depth here but simply mention some trends.

Tuneable UV and visible lasers. UV- and visible-emitting lasers are unavoidable components of submicron lithography processes and optical data storage devices and find applications in holography, microscopy, as well as excitation sources in spectroscopy, to cite a few. They are constructed according to two different principles. One takes advantage of the fact that some $\mathrm{Ln}^{\mathrm{III}}$ ions, e.g. $\mathrm{Ce}^{\mathrm{III}}, \mathrm{Pr}^{\mathrm{III}}, \mathrm{Nd}^{\mathrm{III}}$, or $\mathrm{Tm}^{\mathrm{III}}$, have broad and strong electric-dipole allowed $4 \mathrm{f}-5 \mathrm{~d}$ transitions in the UV and VUV spectral ranges ( $c a$. 220-350 nm), with crosssections reaching $10^{-18} \mathrm{~cm}^{2}$. The energy of these transitions can be easily tuned by varying the host lattice. ${ }^{16}$ Another approach is to resort to up-conversion lasers, in which one rare-earth ion absorbs two infrared photons and transforms them into one visible or UV photon (see example for $\mathrm{Er}^{\mathrm{III}}$ in Fig. 4). A very efficient host for these up-conversion lasers is ZBLAN (zirconium-barium-lanthanum-aluminium-sodium fluorides) glass, not only because of its optical transparency and low background loss $\left(<0.05 \mathrm{~dB} \mathrm{~m}^{-1}\right.$ at $1.5 \mu \mathrm{m}$, $\sim 0.01 \mathrm{~dB} \mathrm{~m}^{-1}$ at $2.5 \mu \mathrm{m}$ ) but also because it can incorporate up to $10 \mathrm{~mol} \%$ of lanthanide (although practical concentrations range between 0.1 and $0.3 \mathrm{~mol} \%$ ). Ions such as $\operatorname{Pr}^{\mathrm{III}}$ (pumped via $\mathrm{Yb}^{\mathrm{III}}$ ), $\mathrm{Nd}^{\mathrm{III}}, \mathrm{Ho}^{\mathrm{III}}, \mathrm{Er}^{\mathrm{III}}$, and $\mathrm{Tm}^{\mathrm{III}}$ provide lasing emission lines between 248 and $808 \mathrm{~nm}$. The $635 \mathrm{~nm}$ $\mathrm{Pr}^{\mathrm{III}}$ line has the largest output power, around $1 \mathrm{~W}$, with an efficiency reaching $19 \%$. These aspects are dealt with in a recent comprehensive review. ${ }^{17}$

Self-frequency doublers. Some lanthanide-containing crystals (essentially $\mathrm{Nd}^{\mathrm{III}}$ but sometimes also $\mathrm{Yb}^{\mathrm{III}}$ ) have nonlinear optical properties and offer feasible alternatives to up-conversion lasers and frequency-doubling crystals. Under appropriate experimental conditions (phase matching, special resonator cavity) part of the NIR laser light can be directly converted into visible light, without the need of having two separate devices, a laser medium and a nonlinear crystal. This leads to more compact and less expensive setups. Examples are $\mathrm{LiNbO}_{3}: \mathrm{Nd}^{\mathrm{III}}$ and $\mathrm{YAl}_{3}\left(\mathrm{BO}_{3}\right)_{4}: \mathrm{Nd}^{\mathrm{III}} \cdot{ }^{16}$

NIR and IR lasers. Numerous hosts and lanthanide ions generate lasing action in these spectral ranges. Some of the best host materials are calcium fluoride ${ }^{18}$ or $\mathrm{ZBLAN}^{17}$ but a wealth of other materials are also feasible. An important factor in their design is to take care that the phonon frequencies are low, typically $<600 \mathrm{~cm}^{-1}$; for instance, ZBLAN has the highest phonon energy around $580 \mathrm{~cm}^{-1}$. The main uses here are telecommunications and eye-safe applications such as telemetry and pollutant detection in atmosphere, or chirurgical operations (e.g. laser surgery of eyes or skin).

Laser cooling and refrigeration. ${ }^{19}$ The principle of laser cooling is the absorption of photons of a given wavelength followed by their re-emission at a slightly shorter wavelength, 
according to an anti-Stokes luminescence process. The extra energy is taken from the phonon reservoir of the material, henceforth cooling it. Since the energy difference is small (at most a few $k T$ values) the excitation bandwidth must be very narrow and only lasers can supply such pumping sources. Since non-radiative de-activation processes will compete with anti-Stokes emission, the problematic point is the same as for the development of lanthanide-based fibre amplifiers and lasers: host materials with very low phonon energies are essential. In this respect, ZBLAN is again a host of choice and indeed, ZBLAN: $\mathrm{Yb}^{\mathrm{III}}(1 \mathrm{~mol} \%)$ holds presently the world record in laser cooling: a bulk sample has been refrigerated from room temperature to $208 \mathrm{~K}$, a $92 \mathrm{~K}$ difference. In this material, the ratio between the ${ }^{2} \mathrm{~F}_{5 / 2} \rightarrow{ }^{2} \mathrm{~F}_{7 / 2}$ transition energy $\left(\sim 9800 \mathrm{~cm}^{-1}\right)$ and the highest-energy phonons, $E_{\mathrm{T}} / \hbar \omega_{\max }$, is equal to $\sim 17$, that is far larger than the ratio of 8 which would lead to $>90 \%$ of the cooling efficiency of the material. $\mathrm{LiYF}_{4}: \mathrm{Yb}^{\mathrm{III}}$ is also an interesting material generating a temperature difference of $69 \mathrm{~K}$ from room temperature. Another $\mathrm{Ln}^{\mathrm{III}}$ ion amenable to this phenomenon is $\mathrm{Tm}^{\mathrm{III}}$ which displays a $24 \mathrm{~K}$ cooling in ZBLAN, while $\mathrm{Er}^{\mathrm{III}}$ in view of its smaller energy gap is much less effective, with temperature differences $<1 \mathrm{~K}$ in various host matrices. In fact, the cooling achieved is very dependent on the purity of the materials. It is expected that with high purity ZBLAN, cooling down to $150 \mathrm{~K}$ may be feasible. However, ZBLAN is not completely optimum since its composition implies 7 components (including the rare-earth dopant), rendering its synthesis tedious. Moreover, its phonon energy is only adequate for $\mathrm{Yb}^{\mathrm{III}}$, so that simpler alternative materials are now being investigated for laser refrigeration. ${ }^{19}$

\section{Solar energy conversion and photocatalysis}

Solar energy is bound to play a crucial role in the energy mix of the future and there are a number of ways to harvest this resource. Here we solely focus on photovoltaics, that is, on the transformation of solar light into electricity. Two different strategies are being pursued.

\subsection{Silicon solar cells}

The first, and older strategy, takes advantage of the peculiar properties of silicon, which has a bandgap of broad absorption in the range $350-1150 \mathrm{~nm}$ allowing it to collect about $50 \%$ of the available sun power. Taking into account the internal quantum efficiency and the various losses such as charge recombination, lattice thermalisation, as well as junction and contact voltage losses, the theoretically calculated limit for external quantum efficiency is $31 \%$ for a single-junction cell (Shockley-Queisser limit). Presently, the best panel performances are around $25 \%$ for single-crystal silicon, $17 \%$ for silicon thin films, and $10 \%$ for amorphous silicon. The cost of these devices presently prevents a large dissemination: first-generation photovoltaic systems using the highest purity materials cost more than 1-2 US $\$$ per W, while secondgeneration devices based on thin films have costs between 1 and $0.5 \$$ per $\mathrm{W}$; it is hoped that third-generation multijunction Si solar cells with down- and up-converters will have a price tag between 0.2 and $0.5 \$$ per $\mathrm{W}^{20}$



Fig. 6 Air mass (AM) 1.5 solar spectrum together with the fraction absorbed by a thick silicon layer as well as the spectral ranges available for down-conversion (DC) and up-conversion (UC). Percentages are for clear sky. Redrawn from ref. 6 and 25 .

The wavelength converters in third-generation cells harvest the UV and NIR spectral ranges of the solar spectrum, as shown in Fig. 6. At first, Si cells were coated with organic dyes to achieve down-conversion (DC), also called quantum cutting (QC) or downshifting (DS), a process in which an energetic photon is "cut" into two (or more) lower-energy photons. But in order to avoid extensive photobleaching, it soon became evident that lanthanide complexes, with either inorganic or organic ligands, could be substituted to simple organic dyes. ${ }^{21}$ Quantum cutting yields between 160 and 190\% are now routinely achieved while they are sometimes close to $200 \%$. How much improvement can be reached by this type of conversion? Trupke and collaborators have theoretically assessed the gain which could be obtained by DC for nonconcentrated solar illumination $(6000 \mathrm{~K})$ and in function of the bandgap $\left(E_{\mathrm{g}}\right)$ of the solar cell. For $E_{\mathrm{g}}=1.1 \mathrm{eV}$ (Si bandgap), the Shockley-Queisser limit of $31 \%$ is extended to $\sim 37 \%$ if the wavelength converter is positioned at the front surface of the solar cell, but if the converter is built on the rear surface, this limit may go up to $\sim 40 \%{ }^{22}$ Quantum cutting with rare-earth doped materials proceeds according to three mechanisms. $^{23}$ (i) Generation of electron-hole (e-h) pairs in the lattice; this requires an electron energy of at least $2.6 \mathrm{eV}$, so that the increase in the internal quantum efficiency is small $(<5 \%$ for $\lambda=350 \mathrm{~nm})$, unless short wavelengths are harvested $(50 \%$ at $\lambda=250 \mathrm{~nm})$. (ii) Generation of two visible photons by a single rare-earth ion; for instance, when the ${ }^{1} \mathrm{~S}_{0}$ level of $\mathrm{Pr}^{\mathrm{III}}$ is excited at $185 \mathrm{~nm}$, this ion emits a blue $(405 \mathrm{~nm})$ and a red $(620 \mathrm{~nm})$ photon with an efficiency of $140 \%$. (iii) Down-conversion with rare-earth pairs; this is exemplified by the absorption of one UV photon by $\mathrm{Gd}^{\mathrm{III}}$ followed by partial transfer of the energy to $\mathrm{Eu}^{\mathrm{III}}$ by cross-relaxation and by regular energy transfer of the remaining part, so that two $612 \mathrm{~nm}$ photons are emitted with an internal quantum efficiency close to $200 \%$ (Fig. 7). However, the very weak absorption of $\mathrm{Gd}^{\mathrm{III}}$ leads to an external quantum efficiency of only $32 \%$. This can nevertheless be substantially improved, up to $110 \%$, by co-doping $\mathrm{Er}^{\mathrm{III}}$ and using $\mathrm{Tb}^{\mathrm{III}}$ instead of $\mathrm{Eu}^{\mathrm{III}}$. The spectroscopy of a wealth of quantum-cutting lanthanide-containing systems is presently being thoroughly investigated in view of their potential applications in Si solar cells. ${ }^{24}$ 


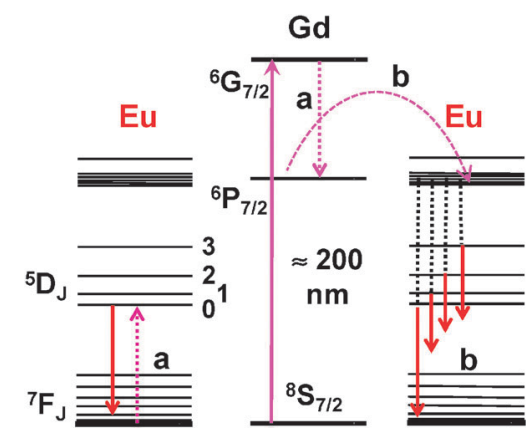

Fig. 7 Principle of quantum cutting (down-conversion) from $\mathrm{Gd}^{\mathrm{III}}$ to $\mathrm{Eu}^{\mathrm{III}}$.

Returning to Fig. 6 and taking spectroscopic properties of lanthanides into account, ${ }^{2}$ one realizes that a good deal of the NIR emission could be transformed into visible light by up-converting rare-earth materials. In these compounds, two photons with energy intermediate between $E_{\mathrm{g}} / 2$ and $E_{\mathrm{g}}$ create one photon with $h \nu \geq E_{\mathrm{g}}$. In fact, the combined available irradiances for DC and UC amount to about half of the total available sun power. Therefore, it is clear that both methods of improving the yield of solar cells should be implemented concurrently. Until now, several up-converting materials, usually involving $\mathrm{Er}^{\mathrm{III}}$, have been proposed for Si solar cells. ${ }^{26}$ As far as conversion yield improvement is concerned, a detailed analysis is available, which takes into account both UC and, instead of DC, a more efficient process called multiexciton generation (MEG) from quantum dots with composition $\mathrm{PbS}, \mathrm{PbSe}, \mathrm{PbTe}$ or $\mathrm{CdSe}$, in which one photon with energy $h \nu \geq n E_{\mathrm{g}}$ yields $n \mathrm{e}-\mathrm{h}$ pairs with energy $\geq E_{\mathrm{g}}$. According to this analysis, the theoretical photovoltaic conversion efficiency for a single bandgap solar cell may be as large as $\sim 40 \%$ if quantum yields of $70 \%$ and $25 \%$ are assumed for MEG and $\mathrm{UC}^{27}$ respectively (note the apparent discrepancy with the figure mentioned above only for DC). But UC is a non-linear process, usually initiated by intense laser irradiation, while solar light is diffuse. ${ }^{28}$ Attention is therefore focusing on solar concentrator layers to overcome this difficulty.

\subsection{Dye-sensitized solar cells}

In the second strategy for harvesting sun energy, organic dyes, transition metal (mainly $\mathrm{Ru}^{\mathrm{II}}$ ) complexes, or quantum dots collect light and sensitize mesoscopic oxide films (typically $\mathrm{TiO}_{2}$ ) having wide band gaps. Anatase is under the form of nanoparticles onto which a monolayer of the harvesting chromophore is deposited. Photo-excitation injects electrons into the conduction band of the oxide and the sensitizer is regenerated by electron donation from an electrolyte consisting of an organic solvent and the iodide/tri-iodide redox couple. Dye-sensitized solar cells (DSSCs) feature easy processability and transparency so that thin films can be designed for various coatings, including window coatings, which opens interesting perspectives. The main problems with these cells are their high cost and low external efficiency, around $8 \%$ for practical modules $\left(25-100 \mathrm{~cm}^{2}\right)$ and $11 \%$ for laboratory devices $\left(1 \mathrm{~cm}^{2}\right) \cdot{ }^{20}$ As for silicon cells these yields could be improved by gathering more of the solar spectrum.
This may be achieved in trying to design dyes with absorption extending in the NIR range of the spectrum, or by resorting to DC and UC (Fig. 8). Although still in its infancy, the use of lanthanide-containing materials in DSSCs starts gaining momentum. For instance, bulk hetero-junction cells fabricated from free base phthalocyanine and samarium phthalocyaninato double and triple deckers as electron donors and a perylenediamine derivative as electron acceptor have the capability of broad-band light harvester, from NIR to UV, but the overall efficiency remains small and such cells will need extensive optimization before they can really be considered as practical light-converting devices. ${ }^{29}$ Another approach has been pioneered by Kim et al., who have introduced a europium complex as energy-converting material in a DSSC working with the reference dye $\mathrm{N} 719^{20}$ (Scheme 1) and have reported an improvement of about $10 \%$ in the conversion efficiency due to DC. ${ }^{30}$ To our knowledge, until now, there is no report on introducing UC materials in DSSCs, but it is obvious that the same type of compounds should be chosen as for Si cells, namely optical nanomaterials incorporating $\mathrm{Yb}^{\mathrm{III}}$ for light harvesting and $\mathrm{Er}^{\mathrm{III}}$ as emitter: this pair of ions convert two $980 \mathrm{~nm}$ photons into a green $(\sim 540 \mathrm{~nm})$ or a red $(\sim 650 \mathrm{~nm})$ photon. It is clear that these possibilities will be thoroughly explored in the near future and will help bringing DSSCs closer to wide use in day-to-day life. A cost/effectiveness analysis will have to be performed though, in view of the price and rarefaction of rare-earth resources. ${ }^{31}$ In this respect, the effectiveness of d-transition metal ion complexes as solar concentrator materials may prove to be a competitor for lanthanides. $^{32}$

\subsection{Photocatalysis}

Due to the daily and seasonable variability of sunlight and to the difficulty of storing electricity, part of the harvested solar energy should be converted into chemical energy which would then be available on demand. In this respect the most straightforward and most sustainable system consists in splitting water by photolysis and storing energy in the simplest chemical bond, $\mathrm{H}_{2}$. Photosynthesis can be achieved in solar

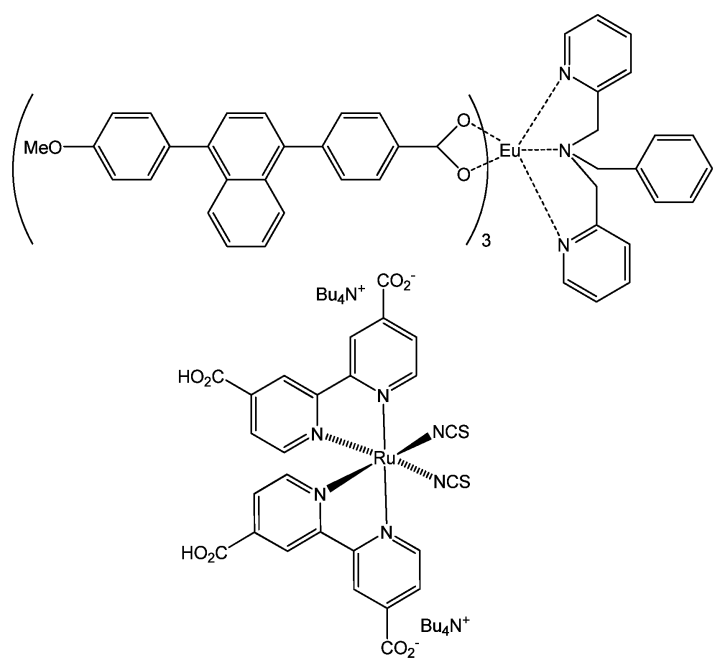

Scheme 1 Formulae of the europium complex used as the wavelength converter in DSSCs and of the reference $\mathrm{Ru}^{\mathrm{II}}$ dye N719. 


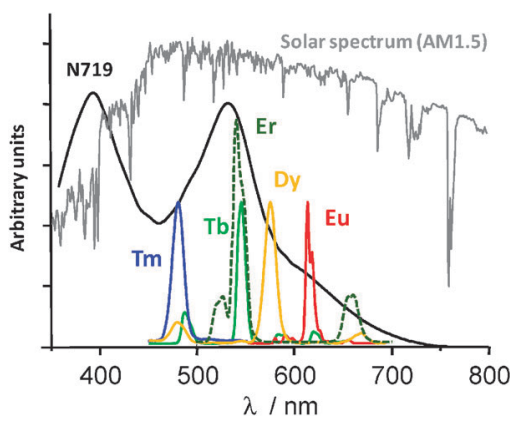

Fig. 8 Emission spectra of some $\mathrm{Ln}^{\mathrm{III}}$ ions used in down-conversion (plain lines) and up-conversion (dotted line) compared with the absorption spectrum of dye N719 and the solar emission spectrum for air mass 1.5 .

water-splitting cells in two ways; one consists in coupling a photovoltaic module to an electrolyser while the other one, simpler and therefore more attractive, accomplishes the splitting at the surface of a conveniently designed semiconductor. The splitting of one mole of water requires $237 \mathrm{~kJ}$ under standard conditions, which translates into a standard potential of $1.23 \mathrm{~V}$. The semi-conductor must therefore absorb light with a wavelength of $<1 \mu \mathrm{m}$ and two photons are required for producing one molecule of $\mathrm{H}_{2}$ at the photocathode. Practically, however, if losses are taken into consideration, the energy required for photoelectrolysis is at least $1.6 \mathrm{eV}$ per electron-hole pair generated, which translates into light with $\lambda<775 \mathrm{~nm}$. For a dual bandgap system, solarto-hydrogen conversion efficiencies on the order of $15 \%$ can be expected. In this context, rare-earth compounds are essentially used as photoanode materials, for instance the perovskite $\mathrm{La}_{2} \mathrm{Ti}_{2} \mathrm{O}_{7}$, or $\mathrm{Y}_{2} \mathrm{Ti}_{2} \mathrm{O}_{7}$ and $\mathrm{Gd}_{2} \mathrm{Ti}_{2} \mathrm{O}_{7}$ with pyrochlore-type structure. $^{33}$

Another application of photocatalysis is the decomposition of pollutants in air and water. Titanium oxide can remove a large number of organic pollutants, including chlorinated pollutants, but its large bandgap $(3.2 \mathrm{eV})$ restricts its use to UV irradiation. Doping with either transition metal cations or anions lowers this bandgap, but the compounds are not as stable as un-doped $\mathrm{TiO}_{2}$. Alternatives are therefore being sought and materials such as $\mathrm{LaTaO}_{4}$ seem to be promising, ${ }^{34}$ as well as $\mathrm{V}-\mathrm{Ln}-\mathrm{O}$ composites which decompose acetone with $80 \%$ yield when $\mathrm{Ln}=\mathrm{Gd}^{\mathrm{III}} \cdot{ }^{35}$ Another elegant solution is to resort to $\mathrm{Ln}^{\mathrm{III}}$ up-conversion, either by doping $\mathrm{TiO}_{2}$ nanoparticles with $\mathrm{Y}_{3} \mathrm{Al}_{5} \mathrm{O}_{12}: \mathrm{Er}^{36}$ or by producing nanoparticles with a $\mathrm{YF}_{3}: \mathrm{Tm}, \mathrm{Yb}$ core and a $\mathrm{TiO}_{2}$ coating. Under solar illumination, $980 \mathrm{~nm}$ light is absorbed by $\mathrm{Yb}^{\mathrm{III}}$ and up-converted by $\mathrm{Tm}^{\mathrm{III}}$ which then emits at 290, 350, 360, 450, and $480 \mathrm{~nm}$, that is in a range suitable for activating $\mathrm{TiO}_{2}{ }^{37}$

\section{Phosphors for displays and lighting}

Since the discovery of the red-emitting $\mathrm{Y}_{2} \mathrm{O}_{3}: \mathrm{Eu}^{\mathrm{III}}$ material by Urbain at the beginning of the 20th century, rare-earth containing light-converting phosphors ${ }^{38}$ have accompanied any development in lighting and display technology. In addition to this red phosphor, the main phosphors in use are $\mathrm{CeMgAl}_{11} \mathrm{O}_{19}: \mathrm{Tb}^{\mathrm{III}}$ or $(\mathrm{La}: \mathrm{Ce}, \mathrm{Tb}) \mathrm{PO}_{4}$ for green and
$\mathrm{BaMgAl}_{10} \mathrm{O}_{17}: \mathrm{Eu}^{\mathrm{II}}$ for blue. The field is vast and technical; we thus only mention the main avenues of current developments.

One important challenge in lighting is to improve the efficiency of the light-converting materials. As the demand increases for high-performance plasma display panels (PDP) and mercury-free fluorescent lamps in which the $\mathrm{He} / \mathrm{Ne}$ discharge generates UV photons with wavelengths in the range $147-190 \mathrm{~nm}$, conversion of these photons into visible light is accompanied by a large energy loss, even if the quantum efficiency is near $100 \%$. This explains the interest for quantum cutting (QC) materials which generate two visible photons upon absorption of one vacuum UV photon. Single ions such as $\mathrm{Pr}^{\mathrm{III}}$ may display QC (or cascade emission), provided that the ${ }^{1} \mathrm{~S}_{0}$ level is below the $4 \mathrm{f} 5 \mathrm{~d}$ band, but the first photon emission $\left({ }^{1} \mathrm{~S}_{0} \rightarrow{ }^{1} \mathrm{I}_{6}\right)$ is at $405 \mathrm{~nm}$, which is not useful for phosphors; Gd ${ }^{\mathrm{III}}, \mathrm{Er}^{\mathrm{III}}$, and $\mathrm{Tm}^{\mathrm{III}}$ also present QC, but the quantum efficiency is rarely larger than $100 \%$. Therefore, most of the practical systems involve combinations of two or three ions and the excited ion transfers partial excitation to two acceptor ions in a process specifically called down-conversion (see Fig. 7 for an example). The basic concepts of quantum cutting, as well as the requirements for materials with this property, are described in the review by Zhang and Huang. $^{24}$

The lighting industry is putting much effort to develop light emitting diodes, both inorganic (LEDs) and organic (OLEDs), and lanthanide materials amenable to electroluminescence play a major role in the design of these devices. Indeed, when purely organic electroluminescent material is used, $75 \%$ of the electroluminescent (EL) excitation energy is lost in that it is used to excite triplet states. Lanthanide ions are good energy harvesters (quenchers) of triplet states and thus allow more electrical energy to be converted into light. A scheme of an OLED is presented in Fig. 9. One class of compounds, $\beta$-diketonates, benefit from much attention because they have short radiative lifetimes and thus are highly luminescent, their volatility makes the fabrication of thin films easier, and their accommodation of a ternary (ancillary) ligand allows finetuning of their photophysical properties. ${ }^{5}$ Latest developments include the incorporation of $\beta$-diketonates into coordination polymers and the tuning of the emitted colour by using a mixture of $\mathrm{Ln}^{\mathrm{III}}$, e.g. $\mathrm{Eu}^{\mathrm{III}}$ and $\mathrm{Tb}^{\mathrm{III}} .39$

Another major axis of development is the search for whitelight emitting OLEDs, which can either be achieved by combining the three fundamental colours (red, green, blue) ${ }^{40}$ or by combining two colours, yellow and blue. ${ }^{41}$
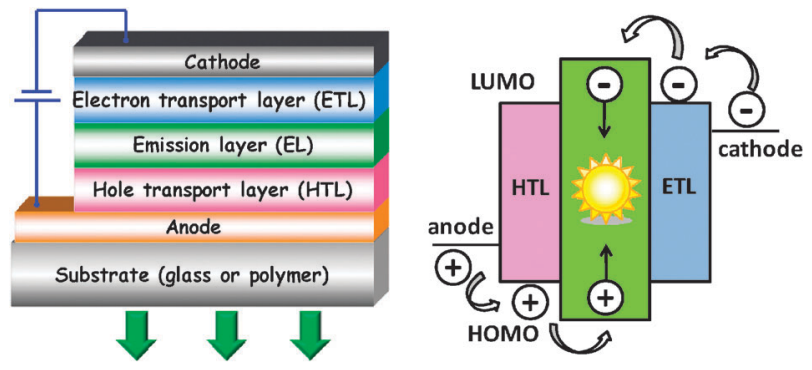

Fig. 9 Design and operating principle of an OLED. Redrawn from ref. 1 and 5 . 


\section{Lanthanide luminescence in biosciences}

Obtaining information on the functional properties of living systems is a key issue in biology and medicine, particularly with respect to individualised therapy. As far as cancer treatment is concerned, for instance, better and faster pathological analyses and highly contrasted real-time bio-images are needed. Gadolinium-based contrast agents are the workhorses of medical imaging and, more recently, responsive probes. ${ }^{42}$ The advent of the chemical exchange saturation transfer technique (CEST) has also brought a new dimension to resonance magnetic bioanalyses. ${ }^{43,44}$ However, optical bioprobes are gaining momentum because when appropriate wavelengths are used their penetration depth may be substantial, allowing the detection of analytes and biomarkers in cells and tissues which are not detectable by other techniques. ${ }^{3,45}$ The contribution of lanthanides to these aspects started more than 30 years ago with luminescent time-resolved immunoassays and is now omnipresent, judging by the impressive number of papers devoted to this type of research as well as of review articles. ${ }^{1,3}$ Indeed, one main advantage of $\mathrm{Ln}^{\mathrm{III}}$ luminescent bioprobes is the long lifetimes of their excited states which allow time-resolved detection. In this way, unwanted autofluorescence of the samples can be eliminated and high signalto-noise ratios achieved. In addition and in contrast to many all-organic probes, the $\mathrm{Ln}^{\mathrm{III}}$ bioprobes are little sensitive to photobleaching. Similar properties could also be expected from quantum dots (QDs); however, in a recent comparative study, up-converting lanthanide-containing nanophosphors (UCNPs) proved to be at least one order of magnitude more sensitive than QDs for in vitro imaging. ${ }^{46}$

UCNPs are now ubiquitous in many facets of bioanalyses and bioimaging and are often replacing the more classical molecular bio-reactants decorated with lanthanide luminescent tags. Their architecture is made up of a core consisting of a rare-earth material, such as $\mathrm{NaYF}_{4}$, doped with the active

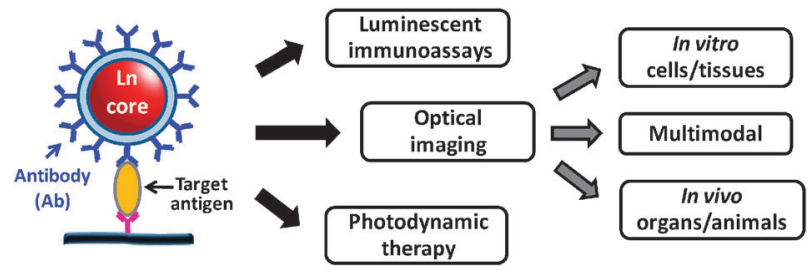

Fig. 10 Applications of UCNPs in bio-analyses and bio-imaging. ${ }^{4}$ lanthanides, commonly $\mathrm{Yb}^{\mathrm{III}}$ and $\mathrm{Er}^{\mathrm{III}}$. This core is then coated with silica to increase hydrophilicity and the obtained surface is derivatised with a suitable antibody for the targeting of specific analytes. Synthetic methods are now well mastered $^{47}$ and multiplex analyses can be designed by modifying both the emitting ion and the antibody. The applicability of UCNPs encompasses a broad range of analyses and is presently extended to photodynamic therapy of cancer, to apoptosis of cancerous cells (induced by the production of reactive oxygen species), as well as to cell and tissue imaging (Fig. 10). ${ }^{2,3}$

Despite the success of UCNPs, molecular luminescent bioprobes retain their attractiveness. For instance, binuclear, self-assembled lanthanide helicates $\left[\mathrm{Ln}_{2} \mathrm{~L}_{3}\right]$ have been developed in the authors' laboratory and proposed as lanthanide luminescent bioprobes. The ligands are hexadentate and derived from bis(benzimidazole)pyridine building blocks which act both as strongly coordinating groups and efficient sensitizing units (Fig. 11). The luminescence of both $\mathrm{Eu}^{\mathrm{III}}$ and $\mathrm{Tb}^{\mathrm{III}}$ is substantially sensitized and, to a lesser extent, emission from $\mathrm{Sm}^{\mathrm{III}}$ and $\mathrm{Yb}^{\mathrm{III}}$ as well. Moreover, the $\left[\mathrm{Ln}_{2}\left(\mathrm{~L}^{\mathrm{C} 2}\right)_{3}\right]$ helicates are non-cytotoxic for several human cell lines while penetrating into them by endocytosis, so that time-resolved luminescence imaging is feasible. ${ }^{48}$ Further derivatization of the polyoxyethylene substituents leads to $\left[\mathrm{Ln}_{2}\left(\mathrm{H}_{2} \mathrm{~L}^{\mathrm{C} 2 \mathrm{C}}\right)_{3}\right]$ helicates $(\mathrm{Ln}=\mathrm{Eu}, \mathrm{Tb})$ which can be bioconjugated to either avidin or monoclonal antibodies. In this way, biomarkers expressed by cancerous cells can be specifically detected, which allows distinction between cancerous and non-cancerous cells. By combining the specificity of these bioconjugates with the advantages of microfluidics, simultaneous detection of two biomarkers expressed by human breast cancer cells, the estrogen receptors (ER) located on the nucleus membrane and the human epidermal growth factor receptors (Her2/neu) lying on the cell membrane, could be achieved (Fig. 12). The helicate luminescence is detected in time-resolved mode and the analysis time is at least 5 times shorter than in the classical protocol, along with a substantial reduction in the reactant volumes used. ${ }^{49}$ It is anticipated that these bioprobes have good future perspectives since they can be excited in the NIR by multiphoton processes ${ }^{50}$ and introduced into silica nanoparticles. $^{51}$

Currently, main focus in the development of lanthanidebased bioprobes is the engineering of dual imaging probes, combining the power of magnetic resonance and optical



Fig. 11 (left) Structure of the hexadentate ligands used in the self-assembly of binuclear luminescent lanthanide helicates. (right) Calculated structure of $\left[\operatorname{Ln}_{2}\left(\mathrm{~L}^{\mathrm{C} 2}\right)_{3}\right]$. 


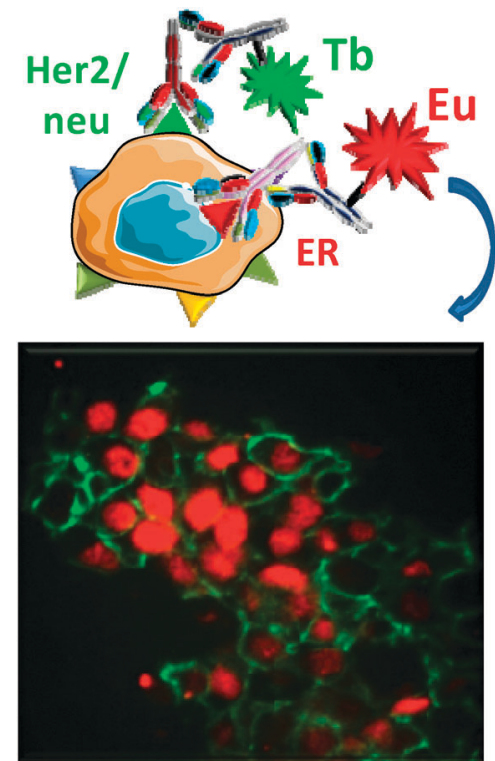

Fig. 12 (top) Principle of the histochemical luminescent assays for the ER and Her2/neu receptors of human breast cancer cells. (right) Time-resolved luminescent microscope image of a human breast cancer tissue section. Redrawn from ref. 49.

imaging techniques, ${ }^{52}$ as well as the design of nanoparticles for temperature sensing in the physiological range, allowing temperature mapping of cells and tissues. ${ }^{53}$

\section{Magnetic materials}

Rare-earth magnetic materials are dominated by highcoercitivity, high-remanence magnets that will not be reviewed here to the profit of two fast-developing aspects of rare-earth materials: single-molecule magnets and magnetic refrigeration.

\subsection{Single-molecule magnets}

Rapid growth in high-speed computers and high-density magnetic storage devices (e.g. hard-disk drives) has induced much interest in nanoscale magnetic materials. Of special interest in this respect are single-molecule magnets (SMMs) which exhibit the same properties as ferromagnetic substances and therefore each molecule may be used to store one bit of information. These molecules combine a high-spin ground state with large axial magnetic anisotropy, resulting in a sizeable barrier for spin reversal and slow-magnetization relaxation rates. Other advantages are their molecular dimensions, very large monodispersivity, and easy processability, allied with relatively low cost. An archetype example of such molecule is $\mathrm{Mn}_{12}$. One essential parameter for SMMs is the blocking temperature, that is, the temperature above which they behave as superparamagnetic molecules. This temperature is presently quite low, which severely limits their application in practical devices. Structural properties and dislocations in the crystal network considerably influence this parameter and are still not well understood. As several lanthanide ions have high spin, they have been naturally selected and tested for introduction into SMMs despite the inherent drawback related to their weak magnetic exchange interactions due to the inner nature of $4 \mathrm{f}$ orbitals.



Fig. 13 Structure of the $\left[\mathrm{Mn}_{5} \mathrm{Dy}_{4}\right]$ complex. Reproduced with permission from ref. 56 (C) Wiley Interscience 2008.

Although an early report described SMM behaviour in a mononuclear $\mathrm{Gd}^{\mathrm{III}}$ double-decker complex with phthalocyanine, the vast majority of the reported compounds exhibiting SMM behaviour feature $\mathrm{Ln}^{\text {III }}$ ions coupled to paramagnetic species. There are basically three possibilities for building lanthanide-containing SMMs: (i) coupling $\mathrm{Ln}^{\text {III }}$ ions with organic radicals such as nitronyl-nitroxide or radicals derived from benzimidazole, e.g. NITpPy (2-(4-pyridyl)4,4,5,5-tetramethyl-4,5-dihydro- $1 H$-imidazolyl-3-oxide) in $\left[\operatorname{Ln}(\mathrm{hfa})_{3}(\mathrm{NITpPy})\right]_{2}$ (hfa is hexafluoroacetylacetonate $)^{7}$ or NIT $m$ bis (1,3-bis-(10-oxyl-30-oxido- $4^{\prime}, 4^{\prime}, 5^{\prime}, 5^{\prime}$-tetramethyl-4,5hydro- $1 H$-imidazol-2-yl)-benzene) in $\left[\mathrm{Dy}(\mathrm{hfa})_{3}(\mathrm{NIT} m \mathrm{bis})\right]_{2},{ }^{54}$ (ii) combining $\mathrm{Ln}^{\mathrm{III}}$ ions with 3 d-transition metal ions, ${ }^{55}$ or (iii) designing polynuclear homometallic $\mathrm{Ln}^{\text {III }}$ clusters. $^{7}$ Regarding $3 \mathrm{~d}-4 \mathrm{f}$ edifices, there are again two possibilities. Firstly, $\mathrm{Gd}^{\mathrm{III}}$ can contribute to increase the spin of d-transition metal clusters which display magnetic anisotropy. On the other hand, anisotropic lanthanide ions, for instance $\mathrm{Tb}^{\mathrm{III}}, \mathrm{Ho}^{\mathrm{III}}$ or, mainly, Dy ${ }^{\text {III }}$, can successfully be coupled to $\mathrm{Cu}^{\mathrm{II}}$ or $\mathrm{Mn}^{\mathrm{II}}$ for generating SMMs. ${ }^{7}$ An example is the $\mathrm{Mn}_{5} \mathrm{Dy}_{4}$ cluster in $\left[\mathrm{Mn}_{5} \mathrm{Dy}_{4}(\mathrm{O})_{6}\left(\mathrm{H}_{2} \mathrm{mdea}\right)_{2}(\mathrm{Hmdea})_{2}(\mathrm{Piv})_{6}\left(\mathrm{NO}_{3}\right)_{4}\left(\mathrm{H}_{2} \mathrm{O}\right)_{2}\right] \cdot 2 \mathrm{MeCN}$ (Fig. 13). In this compound, mdea is $N$-methyldiethanolamine, Piv is 2,2-dimethylpropanoate, and the central ion is $\mathrm{Mn}^{\text {IV }}$ while the other $3 \mathrm{~d}$ ones are $\mathrm{Mn}^{\mathrm{III}}$. The cluster displays a large energy gap of $38.6 \mathrm{~K}$ (equivalent to $26.8 \mathrm{~cm}^{-1}$ ) which is one of the highest spin barrier recorded to date for $4 \mathrm{f}-3 \mathrm{~d}$ SMMs. ${ }^{56}$ When it comes to purely $4 \mathrm{f}$ systems, a trinuclear complex of Dy ${ }^{\text {III }}$ with $o$-vanillin was shown to display spin chirality. ${ }^{7}$ Increasing the nuclearity of Dy clusters seems to be beneficial to the design of SMMs as demonstrated by a tetranuclear oxo-bridged Dy ${ }^{\text {III }}$ cluster which possesses two relaxation mechanisms with large energy barriers of 19.7 and $173 \mathrm{~K}\left(13.7\right.$ and $\left.120 \mathrm{~cm}^{-1}\right){ }^{57}$

\subsection{Magnetocaloric effect and refrigeration}

Cooling and refrigeration are commonly based on compression/expansion cycles which consume a large amount 
of energy and rely on chemical gases detrimental to the environment, more particularly to the ozone layer. To our knowledge, the first use of a rare-earth containing alloy in cooling technology was in 1992 when $\mathrm{Er}_{3} \mathrm{Ni}$ powder spheres were introduced in Gifford-McMahon cryopumps used by the electronic industry as passive magnetic regenerator and allowed the end temperature to be reduced from 10 to $2.5 \mathrm{~K}$. A further step forward was achieved in 1997 when K. A. Gschneidner Jr. and V. K. Pecharsky successfully tested a reciprocating magnetic refrigerator. The machine operated with a permanent $5 \mathrm{~T}$ superconducting magnet having $60 \%$ efficacy with respect to Carnot cycle and could span a temperature range of $38 \mathrm{~K}$. Such a magnetic refrigerator relies on the magnetocaloric effect (MCE, also referred to as adiabatic demagnetization) which was discovered in iron by Warburg in 1881 already. Debye proposed to use it in refrigeration in 1926 , but the available materials only displayed small effects. MCE is the adiabatic temperature change $\Delta T_{\text {ad }}$ occurring upon cooling or heating magnetic materials and is used to reach ultralow temperatures, near $0 \mathrm{~K}$. It is intrinsic to any magnetic material and is due to the coupling of the magnetic sub-lattice with the magnetic field, which influences the magnetic part of the entropy. Its principle is shown in Fig. 14. If the external magnetic field is increased $(H>0)$, the magnetic order increases and the entropy $S$ decreases because the magnetic entropy $S_{\mathrm{M}}$, which is the largest contribution to the total entropy, decreases.

$$
S(T, H)=S_{\mathrm{M}}(T, H)+S_{\mathrm{lat}}(T)+S_{\mathrm{el}}(T)
$$

where $S_{\text {lat }}$ is the lattice entropy and $S_{\text {el }}$ the electronic contribution to entropy. Under adiabatic conditions, that is when the total entropy of the system remains constant, $\Delta T_{\mathrm{ad}}(T, \Delta H)$ is therefore $>0$ and the magnetic materials heat up. Conversely, decreasing $H$ will decrease the magnetic order, increase $S$ and $\Delta T_{\mathrm{ad}}(T, \Delta H)$ becomes therefore negative, the solid cools down. Theoretical considerations led to the following conclusions: (i) the effect will be maximum at Curie temperature $\left(T_{\mathrm{C}}\right)$, (ii) paramagnets will display sizable $\Delta T_{\mathrm{ad}}$ only at temperatures close to absolute zero, and (iii) at elevated temperature, measurable adiabatic heating or cooling is expected only if the solid orders spontaneously. ${ }^{58}$ This is in particular true for metallic $\mathrm{Gd}$ which orders ferromagnetically at $294 \mathrm{~K}\left(T_{\mathrm{C}}\right)$, generating $\Delta T_{\mathrm{ad}}=12 \mathrm{~K}$ at $\Delta H=5 \mathrm{~T}$. Many

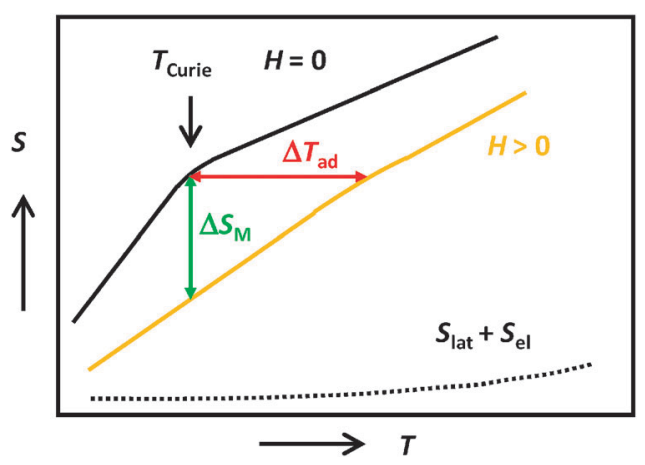

Fig. 14 Principle of the magnetocaloric effect (see text for explanations). Redrawn after ref. 58. alloys and intermetallic compounds have been tested, but only Gd and $\mathrm{Gd}_{5} \mathrm{Si}_{4}$ displayed a large MCE.

This was, however, only true until 1997 when the series of $\mathrm{Gd}_{5}\left(\mathrm{Si}_{x} \mathrm{Ge}_{1-x}\right)_{4}(0<x<0.5)$ alloys were discovered and shown to display a magnetocaloric effect at least two times as large as Gd (giant MCE). These alloys are unique in that their Curie temperature can be tuned between $\sim 20$ and $\sim 286 \mathrm{~K}$ by varying $x$ and by introducing small amounts of Ga. Moreover the giant MCE does not disappear after applying the magnetic field for the first time and such a reversibility is of course needed for designing magnetocaloric cooling machines. ${ }^{58,59}$ Magnetic cooling involves four steps and the porous bed of paramagnetic materials acts both as the coolant and the regenerator for the heat transfer. In Fig. 15, it is assumed that the hot exchanger is at about $24{ }^{\circ} \mathrm{C}$ and the cold exchanger at about $5{ }^{\circ} \mathrm{C}$. When the magnetic field is switched on (step 1) MCE causes the bed particles to warm up. Then, a heat transfer fluid is flowed through the bed from the cold to the hot sections (step 2), removing heat. In step 3, the magnetic field is switched off, which cools the paramagnetic bed by MCE. The cycle is completed by flowing the fluid in the reverse direction (step 4). ${ }^{60}$

Several commercial refrigerators have now been built on this principle and are operating throughout the world, mainly using $\mathrm{Gd}$ as a magnetic coolant. Since the discovery of $\mathrm{Gd}_{5}\left(\mathrm{Si}_{x} \mathrm{Ge}_{1-x}\right)_{4}$ phases, several other binary and ternary intermetallic materials based on lanthanum, gadolinium, or manganese have been found which also display sizeable MCE. ${ }^{59}$ The search for such materials remains very active and promising, as demonstrated by the finding that luminescent $\mathrm{Er}_{0.3} \mathrm{~Pb}_{0.7} \mathrm{~F}_{2.3}$ nanoparticles have potential for magnetically induced nanoscale refrigeration, which would allow combining optical and magnetic properties in one material. ${ }^{61}$
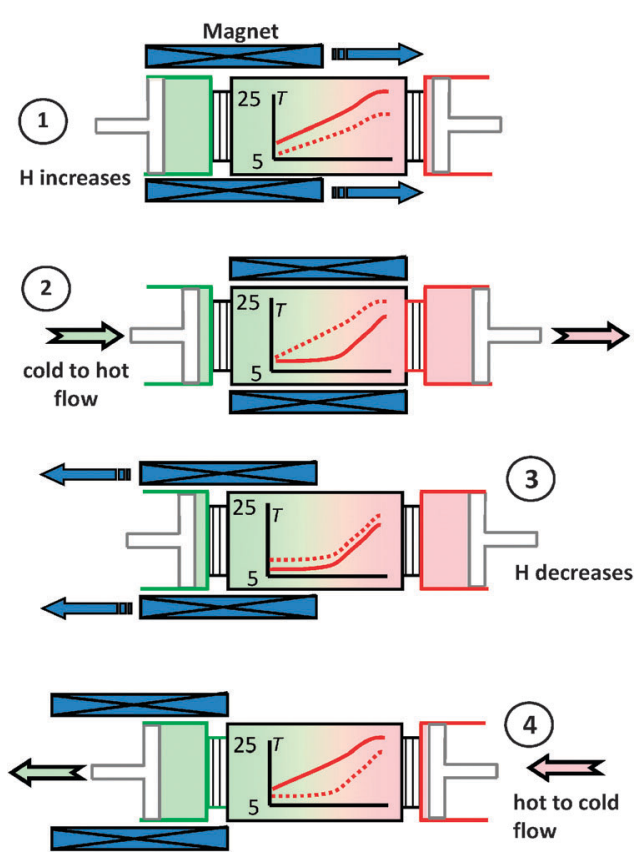

Fig. 15 The four steps of magnetic cooling. Initial and final temperatures along the magnetic bed are given by the dotted and plain lines, respectively. Redrawn from ref. 60 . 


\section{Perspectives}

Although incomplete and somewhat superficial, this overview of some practical materials containing rare earths demonstrates the broad field of application of these elements, principally due to their fascinating optical and magnetic properties. The present tensions on the markets mainly arise from geopolitical reasons and not because a real shortage of these resources is in sight (except, maybe for a few elements such as Dy, or Gd if it would be employed in any refrigeration machine worldwide). Therefore, efforts towards the finding of new properties and new materials will be continued and many fields, in particular the emerging energy-conversion and biomedical markets, will benefit from these elements. Also more clever nanomaterials and inorganic-organic hybrids ought to be developed, which minimize the use of these elements while keeping (or even improving) their physical and chemical properties. The prospect is therefore bright for rare-earth related science, which should encourage young investigators of all fields of science, from geology to medicine, to join the rare-earth community.

\section{Acknowledgements}

This research is supported through grants from the Swiss National Science Foundation; JCB thanks the WCU program from the National Science Foundation of Korea for grant R31-10035; SE thanks FWO-Flanders for a Postdoctoral Fellowship.

\section{References}

1 S. V. Eliseeva and J.-C. G. Bünzli, Chem. Soc. Rev., 2010, 39, 189

2 J.-C. G. Bünzli and S. V. Eliseeva, J. Rare Earths, 2010, 28, 824.

3 J.-C. G. Bünzli, Chem. Rev., 2010, 110, 2729.

4 F. Wang, D. Banerjee, Y. Liu, X. Chen and X. Liu, Analyst, 2010, 135, 1839.

5 M. A. Katkova and M. N. Bochkarev, Dalton Trans., 2010, 39, 6599.

6 B. M. van der Ende, L. Aarts and A. Meijerink, Phys. Chem. Chem. Phys., 2009, 11, 11081.

7 R. Sessoli and A. K. Powell, Coord. Chem. Rev., 2009, 253, 2328.

8 K. Binnemans, Chem. Rev., 2009, 109, 4283.

9 M. C. Paul, S. W. Harun, N. A. D. Huri, A. Hamzah, S. Das, M. Pal, S. K. Bhadra, H. Ahmad, S. Yoo, M. P. Kalita, A. J. Boyland and J. K. Sahu, Opt. Lett., 2010, 35, 2882.

10 S. Comby and J.-C. G. Bünzli, in Handbook on the Physics and Chemistry of Rare Earths, ed. K. A. Gschneidner Jr., J.-C. G. Bünzli, and V. K. Pecharsky, Elsevier Science BV, Amsterdam, 2007, vol. 37, ch. 35, pp. 217-470.

11 J. B. Oh, M. K. Nah, Y. H. Kim, M. S. Kang, J. W. Ka and H. K. Kim, Adv. Funct. Mater., 2007, 17, 413.

12 K. L. Lei, C. F. Chow, K. C. Tsang, E. N. Y. Lei, V. A. L. Roy, M. H. W. Lam, C. S. Lee, E. Y. B. Pun and J. Li, J. Mater. Chem., 2010, 20, 7526.

13 M. Leich, U. Ropke, S. Jetschke, S. Unger, V. Reichel and J. Kirchhof, Opt. Express, 2009, 17, 12588.

14 F. Just, H. R. Muller, S. Unger, J. Kirchhof, V. Reichel and H. Bartelt, J. Lightwave Technol., 2009, 27, 2111.

15 R. A. S. Ferreira, P. S. André and L. D. Carlos, Opt. Mater. (Amsterdam), 2010, 32, 1397.

16 R. Moncorge, in Spectroscopic Properties of Rare Earths in Optical Materials, ed. G. K. Liu and B. Jacquier, Springer Verlag, Berlin, 2005, vol. 83, ch. 6, pp. 320-78.

17 X. Zhu and N. Peyghambarian, Adv. OptoElectron., 2010, 501956.

18 J. L. Doualan, P. Camy, R. Moncorge, E. Daran, M. Couchaud and B. Ferrand, J. Fluorine Chem., 2007, 128, 459.
19 M. P. Hehlen, in Optical Refrigeration: Science and Applications of Laser Cooling of Solids, ed. I. R. Epstein and M. Sheik-Bahae, Wiley-VCH, Mannheim, 2009, pp. 33-74.

$20 \mathrm{~K}$. Kalyanasundaram, in Dye-sensitized Solar Cells, ed. K. Kalyanasundaram, EPFL Press, Lausanne, 2010, ch. 1, pp. 1-44.

21 B. M. van der Ende, L. Aarts and A. Meijerink, Adv. Mater., 2009, 21, 3073.

22 T. Trupke, M. A. Green and P. Wurfel, J. Appl. Phys., 2002, 92, 1668.

23 B. S. Richards, Sol. Energy Mater. Sol. Cells, 2006, 90, 1189.

24 Q. Y. Zhang and X. Y. Huang, Prog. Mater. Sci., 2010, 55, 353.

25 B. S. Richards, Sol. Energy Mater. Sol. Cells, 2006, 90, 2329.

26 S. Ivanova and F. Pelle, J. Opt. Soc. Am. B, 2009, 26, 1930.

27 H. Shpaisman, O. Niitsoo, I. Lubomirsky and D. Cahen, Sol. Energy Mater. Sol. Cells, 2008, 92, 1541.

28 M. Liao, G. Qin, X. Yan, M. Hughes, T. Suzuki and Y. Ohishi, J. Opt. Soc. Am. B, 2010, 27, 1352.

29 Q. Wang, Y. Li, X. Z. Yan, M. Rathi, M. Ropp, D. Galipeau and J. Z. Jiang, Appl. Phys. Lett., 2008, 93, 073303.

30 J. H. Oh, H. M. Song and H. K. Kim, Abstracts First International Conference on Luminescence of Lanthanides, Odessa, Ukraine, Sept. 5-9, 2010, 88.

31 R. F. Service, Science, 2010, 327, 1596.

32 M. J. Currie, J. K. Mapel, T. D. Heidel, S. Goffri and M. A. Baldo, Science, 2008, 321, 226.

33 M. G. Walter, E. L. Warren, J. R. McKone, S. W. Boettcher, Q. Mi, E. A. Santori and N. S. Lewis, Chem. Rev., 2010, 110, 6446.

34 M. Nyman, M. A. Rodriguez, L. E. S. Rohwer, J. E. Martin, M. Waller and F. E. Osterloh, Chem. Mater., 2009, 21, 4731.

35 Y. M. He, Y. Wu, T. L. Sheng and X. T. Wu, J. Hazard. Mater., $2010, \mathbf{1 8 0}, 675$.

36 G. F. Feng, S. W. Liu, Z. L. Xiu, Y. Zhang, J. X. Yu, Y. G. Chen, P. Wang and X. J. Yu, J. Phys. Chem. C, 2008, 112, 13692.

37 W. Qin, D. Zhang, D. Zhao, L. Wang and K. Zheng, Chem. Commun., 2010, 46, 2304.

38 L. D. Carlos, R. A. S. Ferreira, V. de Zea Bermudez, B. Julian-Lopez and P. Escribano, Chem. Soc. Rev., 2011, 40, 536.

39 S. V. Eliseeva, D. N. Pleshkov, K. A. Lyssenko, L. S. Lepnev, J.-C. G. Bünzli and N. P. Kuzmina, Inorg. Chem., 2010, 49, 9300 .

40 L. Armelao, G. Bottaro, S. Quici, C. Scalera, M. Cavazzini, G. Accorsi and M. Bolognesi, ChemPhysChem, 2010, 11, 2499.

41 N. Guo, Y. Huang, H. You, M. Yang, Y. Song, K. Liu and Y. Zheng, Inorg. Chem., 2010, 49, 10907.

42 J. L. Major and T. J. Meade, Acc. Chem. Res., 2009, 42, 893.

43 S. Viswanathan, Z. Kovacs, K. N. Green, S. J. Ratnakar and A. D. Sherry, Chem. Rev., 2010, 110, 2960.

44 M. M. Ali, G. Liu, T. Shah, C. A. Flask and M. D. Pagel, Acc. Chem. Res., 2009, 42, 915.

45 K. N. Allen and B. Imperiali, Curr. Opin. Chem. Biol., 2010, 14, 247.

46 L. Cheng, K. Yang, S. Zhang, M. Shao, S. Lee and Z. Liu, Nano Res., 2010, 3, 722.

47 C. Zhang, L. D. Sun, Y. W. Zhang and C. H. Yan, J. Rare Earths, 2010, 28, 807.

48 B. Song, C. D. B. Vandevyver, A.-S. Chauvin and J.-C. G. Bünzli, Org. Biomol. Chem., 2008, 6, 4125.

49 V. Fernandez-Moreira, B. Song, V. Sivagnanam, A.-S. Chauvin, C. D. B. Vandevyver, M. A. M. Gijs, I. A. Hemmilä, H.-A. Lehr and J.-C. G. Bünzli, Analyst, 2010, 135, 42.

50 S. V. Eliseeva, G. Auböck, F. van Mourik, A. Cannizo, B. Song, E. Deiters, A.-S. Chauvin, M. Chergui and J.-C. G. Bünzli, J. Phys. Chem. B, 2010, 114, 2932.

51 S. V. Eliseeva, B. Song, C. D. B. Vandevyver, A.-S. Chauvin, J. B. Wacker and J.-C. G. Bünzli, New J. Chem., 2010, 34, 2915.

52 C. S. Bonnet and E. Toth, C. R. Hebd. Séances Acad. Sci., 2010, 13, 700 .

53 H. Peng, M. I. J. Stich, J. Yu, L. N. Sun, L. H. Fischer and O. S. Wolfbeis, Adv. Mater., 2010, 22, 716.

54 K. Bernot, F. Pointillart, P. Rosa, M. Etienne, R. Sessoli and D. Gatteschi, Chem. Commun., 2010, 46, 6458.

55 M. Andruh, J.-P. Costes, C. Diaz and S. Gao, Inorg. Chem., 2009, 48, 3342 . 
56 V. Mereacre, A. M. Ako, R. Clerac, W. Wernsdorfer, I. J. Hewitt, C. E. Anson and A. K. Powell, Chem.-Eur. J., 2008, 14 3577.

57 Y. N. Guo, G. F. Xu, P. Gamez, L. Zhao, S. Y. Lin, R. Deng, J. Tang and H. J. Zhang, J. Am. Chem. Soc., 2010, 132, 8538.

58 K. A. Gschneidner Jr., V. K. Pecharsky and A. O. Pecharsky, Rep. Prog. Phys., 2005, 68, 1479.
59 G. J. Miller, Chem. Soc. Rev., 2006, 35, 799.

60 V. K. Pecharsky and K. A. Gschneidner Jr., J. Magn. Magn. Mater., 1999, 200, 44.

61 W. Van den Heuvel, V. K. Tikhomirov, D. Kirilenko, N. Schildermans, L. F. Chibotaru, J. Vanacken, P. Gredin, M. Mortier, G. van Tendeloo and V. V. Moshchalkov, Phys. Rev. B: Condens. Matter, 2010, 82, 094421. 